\title{
Nutritional enhancement of total lipid, n-3 and n-6 fatty acids in Artemia urmiana nauplii by enriching with ICES/30/4
}

\begin{abstract}
Artemia urmiana nauplii were enriched with three different concentrations (100, 200 and 300 ppm) of commercial emulsion, ICES/30/4 during two periods (12 and $24 \mathrm{~h}$ ) to evaluate the enhancement of its Highly Unsaturated Fatty Acids (HUFAs). This source was selected because of its high concentration of the longest chain HUFA's in the n-3 and n-6 series. When 24-h-old Artemia nauplii were enriched with $100 \mathrm{ppm}$ concentration of ICES30/4 during $12 \mathrm{~h}$ enriching period, the docosahexanoic acid (DHA), eicosapentaenoic acid (EPA) and arachidonic acid (ARA) contents of the nauplii increased to $0.77,1.22$ and 0.34 and when enriched with $300 \mathrm{ppm}$ during $24 \mathrm{~h}$ increased to $5.99,4.97$ and $0.73 \mathrm{mg} \mathrm{g}(-1)$ dry weight, respectively. DHA, EPA and ARA in control nauplii were $0.00,0.82$ and $0.61 \mathrm{mg} \mathrm{g}(-1)$ dryweight, respectively. Total lipid increased from $16.79 \%$ in control group to $20.87 \%$ in the treatment ICES30/4 24-300. The results suggest that high amount of emulsion and prolong the enriching period are effective in enriching Artemia nauplii in both DHA and EPA increasingly $(\mathrm{p}<0.05)$ but in other fatty acids, there are differences only among period treatments $(p<0.05)$ and concentration are not any increasing effective. There are only differences among concentration treatments in total lipid $\mathrm{p}<0.05$ ) and enriching period do not show any differences.
\end{abstract}

Keyword: Enhancement HUFA; Emulsion level; Enrichment periods; Nutrition. 